\title{
ISOLASI DAN IDENTIFIKASI SENYAWA ANTIOKSIDAN GOLONGAN FLAVONOID DARI EKSTRAK ETIL ASETAT DAUN PRANAJIWA (Euchresta horsfieldii Lesch Benn.)
}

\author{
Ni Wayan Rika Kumara Dewi ${ }^{1 *}$, I Wayan Gunawan ${ }^{1,2}$, Ni Made Puspawati ${ }^{1,2}$ \\ ${ }^{1}$ Magister Kimia Terapan, Pascasarjana Universitas Udayana, Jl. PB. Sudirman, Denpasar, Indonesia \\ ${ }^{2}$ Jurusan Kimia FMIPA, Universitas Udayana, Bukit Jimbaran, Denpasar, Telp (0361)703137, Indonesia \\ "E-mail: rikakumara87@gmail.com
}

\begin{abstract}
ABSTRAK: Penelitian ini bertujuan untuk menentukan aktivitas antioksidan dan mengidentifikasi senyawa golongan flavonoid yang terkandung dalam ekstrak etil asetat daun pranajiwa (Euchresta horsfieldii Lesch Benn.). Uji aktivitas antioksidan dilakukan secara invitro dengan metode DPPH (1,1-diphenyl-2-pycrylhidrazyl). Teknik pemisahan dilakukan dengan kromatografi kolom dan diidentifikasi dengan spektrofotometer FTIR dan UV-Vis. Hasil penelitian menunjukkan bahwa ekstrak etil asetat memiliki aktivitas antioksidan dengan nilai $\mathrm{IC}_{50}$ sebesar 393,95 $\mu \mathrm{g} / \mathrm{mL}$ dan kadar total flavonoid sebesar 6619,72 $\mathrm{mg} Q E / 100 \mathrm{~g}$ atau $6,62 \% Q E$. Pemisahan dan pemurnian ekstrak etil asetat menggunakan fase diam silika gel 60 dan fase gerak n-heksana:kloroform: etanol (20:1:1) yang menghasilkan isolat aktif yang positif flavonoid (isolat $\mathrm{F}_{\mathrm{E}}$ ) yang diduga merupakan senyawa flavonoid golongan flavonol yaitu 3,5,7,3',4'-pentahidroksi flavonol.
\end{abstract}

Kata kunci : Eucresta horsfieldii Lesch Benn., antioksidan, flavonol

\begin{abstract}
The present study was conducted to determine antioxidant activity and to identify the flavonoid active compounds from ethyl acetate extracts of Pranajiwa leaves. In vitro antioxidant activity was carried out using DPPH (1,1-diphenyl-2-pycrylhidrazyl) method. The separation of the ethyl acetate extracts was conducted by column chromatography and the identification by using FTIR and UV-Vis spectrophotometer. The results showed that ethyl acetate extract has antioxidant activity with $\mathrm{IC}_{50}$ value of 393,95 $\mu \mathrm{g} / \mathrm{mL}$ and the total flavonoid of $6619,72 \mathrm{mg} \mathrm{QE} / 100 \mathrm{~g}$ or $6,62 \% \mathrm{QE}$. The separation and purification of ethyl acetate extract was chromatography column on silica gel 60 and the solvent n-hexane:chloroform:ethanol (20:1:1) based on UV-Vis and Infrared spectra positive flavonoid isolate (isolates $\mathrm{F}_{\mathrm{E}}$ ) was tentaviely identified as 3,5,7,3',4'-pentadihydroxy flavonols.
\end{abstract}

Keywords: Eucresta horsfieldii Lesch Benn., antioxidant, flavonols 


\section{PENDAHULUAN}

Indonesia adalah salah satu negara yang beriklim tropis, sehingga berbagai jenis tumbuhan dapat hidup dan berkembang. Berbagai jenis tumbuhan tersebut diketahui memiliki khasiat sebagai obat tradisional. Tumbuhan Pranajiwa (Euchresta horsfieldii Lesch Benn.) merupakan salah satu tumbuhan tradisional yang digunakan untuk obat kencing manis, obat asma, obat batuk, afrodisiak, dan merangsang muntah akibat keracunan makanan [1]. Akar dan batang tumbuhan pranajiwa mengandung flavonoid, isoflavon, pterocarpan, caumaronochromon dan flavonon. Jenis flavonoid yang terdapat pada daun adalah apigenin. Bijinya mengandung alkaloid berupa cytosine $(1,5 \%)$, matrine dan matrine-N-oxide [2,3]. Senyawa golongan flavonoid merupakan salah satu jenis senyawa yang memiliki aktivitas antioksidan. Flavonoid berpotensi sebagai antioksidan karena mampu menyumbangkan ion $\mathrm{H}^{+}$pada senyawa radikal bebas [4].

Hal ini di dukung oleh beberapa hasil penelitian yaitu pada fraksi n-butanol terong belanda memiliki aktivitas antioksidan yang kuat dengan nilai $\mathrm{IC}_{50}$ sebesar 69,89 mg/L. Fraksi n-butanol tersebut diduga mengandung senyawa flavonoid golongan flavon, flavonol, dan isoflavon yang mungkin berkontribusi sebagai antioksidan alami [5].

Isolat aktif ekstrak $n$-heksana daun pranajiwa pada konsentrasi 8000 ppm, diketahui memiliki aktivitas antiradikal bebas dengan persentase peredaman sebesar 94,67\% [6]. Selain itu diketahui pada ekstrak n-heksana daun pranajiwa memiliki kapasitas antioksidan sebesar 126,94 ppm GAEAC (Garlic Acid Equivalent Antioxidant Capacity) [7].

Berdasarkan beberapa penelitian tersebut, dapat dinyatakan daun pranajiwa merupakan salah satu sumber antioksidan, akan tetapi belum ada penelitian yang melaporkan kandungan flavonoid pada ekstrak etil asetat daun pranajiwa serta kontribusinya sebagai antioksidan.
Penelitian ini bertujuan untuk menentukan aktivitas antioksidan dan mengidentifikasi senyawa golongan flavonoid yang terkandung dalam ekstrak etil asetat daun pranajiwa.

\section{PERCOBAAN}

\section{Bahan dan Peralatan}

Bahan yang digunakan dalam penelitian ini adalah daun pranajiwa (Euchresta horsfieldii Lesch Benn.) yang diperoleh dari Bukit Tapak, Bedugul, Tabanan. Bahan-bahan yang digunakan untuk analisis adalah kristal DPPH $(1,1$ diphenyl-2-pycrylhidrazyl), n-heksana, etil asetat, asam klorida pekat, kloroform, etanol, asam sulfat pekat, asetat anhidrat, pereaksi Wagner, pereaksi Meyer, $\mathrm{FeCl}_{3}$, natrium hiroksida, aluminium klorida, serbuk magnesium, kuersetin, asam galat, dan akuades.

Alat-alat yang digunakan adalah seperangkat peralatan gelas, rotary vacuum evaporator, spektrofotometer UV-Vis Double Beam Shimadzu/UV-1800, spektrofotometer UV-Vis Thermo Scientific Genesys 10S, dan spektrofotometer FTIR Shimadzu/IR Prestige-21.

\section{Ekstraksi}

Sebanyak 2,5 kg daun pranajiwa dicuci dan dipotong kecil-kecil, selanjutnya kemudian dikering anginkan selama \pm 5 hari. Sampel yang sudah kering tersebut dihaluskan sehingga diperoleh bahan dalam bentuk serbuk. Serbuk tersebut dimaserasi dengan pelarut $n$-heksana selama 48 jam dan dimaserasi lagi sebanyak lima kali, sehingga diperoleh ekstrak kental $n$ heksana. Ekstrak kemudian disaring dan filtratnya kemudian dipekatkan dengan rotary evapotarator pada temperatur $45^{\circ} \mathrm{C}$ sehingga diperoleh ekstrak kental $n$ heksana. Ampas dari hasil maserasi tersebut kembali dimaserasi dengan etil asetat sehingga diperoleh juga ekstrak kental etil asetat. Setelah diperoleh ekstrak 
kental, dilakukan uji fitokimia untuk mengetahui kandungan metabolit sekunder yang terdapat dalam ekstrak kental etil asetat. Jika ekstrak kental etil asetat positif mengandung flavonoid, maka dilanjutkan dengan penentuan kandungan total flavonoid.

\section{Pengukuran Total Flavonoid}

Kandungan total flavonoid ditentukan dengan metode kolorimetri dengan aluminium klorida. Sebanyak $1 \mathrm{mg}$ standar kuersetin dilarutkan dalam labu ukur $10 \mathrm{~mL}$ dengan etanol sampai tanda batas. Selanjutnya dibuat larutan seri dengan konsentrasi 1; 2; 4; 8; dan 10 ppm. Larutan baku standar kuersetin 100 ppm dipipet masing-masing $10 ; 20 ; 40 ; 80 ; 100 \mu \mathrm{L}$. Sebanyak 5,23 mg ekstrak kental etil asetat daun pranajiwa ditimbang dan dilarutkan dengan etanol dalam labu ukur $10 \mathrm{~mL}$ sampai tanda batas. Larutan tersebut selanjutnya dikocok dan disaring. Masingmasing larutan seri standar kuersetin dan sampel diambil sebanyak $2 \mathrm{~mL}$ selanjutnya ditambahkan dengan $2 \mathrm{~mL}$ aluminium klorida $2 \%$ yang telah dilarutkan dengan etanol. Campuran larutan tersebut selanjutnya divortex selama 20 menit dan diinkubasi selama 24 menit. Absorbansi dari campuran larutan tersebut kemudian diukur pada panjang gelombang $415 \mathrm{~nm}$. Pengukuran dilakukan sebanyak tiga kali [8].

\section{Pengukuran Aktivitas Antioksidan dengan DPPH}

Uji aktivitas antioksidan menggunakan asam galat sehingga satuan pengukuran dinyatakan sebagai GAEAC (Gallic Acid Equivalent Antioxidant Capacity). Untuk melakukan penentuan kadar kapasitas antioksidan dari ekstrak etil asetat yang diuji, dilakukan melalui pembuatan kurva standar asam galat, dengan melakukan pengukuran absorbansi dari larutan standar DPPH dengan beberapa seri konsentrasi yaitu $0,2,4,6,8$, dan $10 \mathrm{mg} / \mathrm{L}$. Sampel dan standar asam galat masing-masing sebanyak $0,5 \mathrm{~mL}$ ditambahkan $3,5 \mathrm{~mL}$ larutan pereaksi DPPH, divortex agar homogen. Didiamkan selama 30 menit kemudian dibaca serapan aktivitasnya pada panjang gelombang $517 \mathrm{~nm}$. Asam galat digunakan sebagai baku pembanding [9].

\section{Pemisahan dan Pemurnian}

Pemisahan dan pemurnian senyawa flavonoid dapat dilakukan dengan menggunakan Kromatografi Lapis Tipis dan Kromatografi kolom sampai diperoleh isolat yang positif flavonoid dan relatif murni. Eluen yang digunakan pada kromatografi kolom adalah $n$-heksana : kloroform : etanol (20:1:1).

\section{Identifikasi Senyawa Flavonoid}

Hasil isolat yang didapatkan dari kromatografi kolom dianalisis dan diidentifikasi menggunakan spektrofotometer ultra violet-visible dengan penambahan pereaksi geser dan dilakukan identifikasi dengan menggunakan spektrofotometer FTIR.

\section{HASIL DAN PEMBAHASAN}

\section{Ekstraksi}

Dari 2,5 $\mathrm{Kg}$ daun pranajiwa diperoleh bahan dalam bentuk serbuk sebanyak 580 g. Serbuk tersebut dimaserasi sehingga diperoleh ekstrak kental $n$-heksana sebanyak 5,18 g. Ampas dari hasil maserasi tersebut kembali dimaserasi dengan etil asetat sehingga diperoleh juga ekstrak kental etil asetat sebanyak 13,16 g. Ekstrak kental etil asetat yang diperoleh memberikan hasil yang positif untuk senyawa golongan flavonoid, alkaloid, steroid, dan fenol.

\section{Total Flavonoid}

Hasil analisis terhadap larutan kuersetin menunjukkan kurva baku dengan persamaan regresi linear $\mathrm{y}=0,080 \mathrm{x}+$ 0,017 dengan harga koefisien korelasi $\left(\mathrm{R}^{2}\right)$ sebesar 0,997. Hasil pengukuran kandungan total flavonoid pada ekstrak etil asetat daun pranajiwa sebesar 6619,72 $\mathrm{mg} / 100 \mathrm{~g} Q E$. Kandungan flavonoid total 
dalam tumbuhan dinyatakan dalam $Q E$ (quercetin equivalent) yaitu jumlah kesetaraan milligram kuersetin dalam 1 gram ekstrak. Analisis kandungan total flavonoid dihitung sebagai ekuivalen kuersetin dalam \% (b/b) sebesar 6,62\% yang berarti tiap $100 \mathrm{~g}$ ekstrak etil asetat daun pranajiwa mengandung 6,62 $\mathrm{g}$ kuersetin.

\section{Aktivitas Antioksidan}

Dari nilai pengukuran absorbansi larutan standar DPPH yang dilakukan, diperoleh hubungan yang berbanding terbalik antara konsentrasi dengan nilai absorbansi. Semakin besar konsentrasi larutan standar yang diukur, nilai absorbansi yang diperoleh semakin kecil. Absorbansi terbesar diperoleh dari larutan blanko yaitu pereaksi DPPH kemudian terjadi penurunan nilai absorbansi dengan semakin besarnya konsentrasi dari larutan standar DPPH yang diuji. Dari kurva standar dapat diketahui hubungan antara absorbansi dan konsentrasi, dan nilai persamaan koefisien regresi $\mathrm{y}=-0,064 \mathrm{x}+$ 0,891 . Dari persamaan regresi linier ini kemudian ditentukan konsentrasi dari ekstrak kental etil asetat yang diuji yang nantinya digunakan dalam perhitungan dalam mencari nilai kapasitas antioksidan ekstrak (\% GAEAC).

Kapasitas antioksidan menyatakan jumlah antioksidan yang terkandung dalam

suatu sampel. Parameter dalam penentuan kapasitas antioksidan adalah dengan menentukan besar daya hambat antioksidan terhadap radikal bebas yang dinyatakan dalam $\% \quad \mathrm{IC}_{50}$. Nilai $\mathrm{IC}_{50}$ ini dijadikan acuan untuk menentukan konsentrasi ekstrak yang diperlukan untuk dapat menangkap $50 \%$ radikal bebas. Hasil pengukuran kapasitas antioksidan pada ekstrak etil asetat daun pranajiwa yang diperoleh yaitu sebesar 1,961 \% b/b GAEAC atau $19610 \mathrm{mg} / 100 \mathrm{~g}$ GAEAC.

Berdasarkan hasil pengukuran menunjukkan bahwa ekstrak etil asetat daun pranajiwa memiliki nilai $\mathrm{IC}_{50}$ sebesar
$393,95 \mu \mathrm{g} / \mathrm{mL}$, yang artinya dengan 393,95 $\mu \mathrm{g} / \mathrm{mL}$ antioksidan telah mampu meredam 50\% radikal DPPH. Berdasarkan studi literatur juga menyatakan bahwa suatu zat mempunyai sifat antioksidan bila nilai $\mathrm{IC}_{50}$ yang diperoleh berkisar antara 200-1000 $\mathrm{g} / \mathrm{mL}$, dimana zat tersebut kurang aktif namun masih berpotensi sebagai zat antioksidan [10]. Aktivitas antioksidan ekstrak etil asetat daun pranajiwa tergolong lemah, hal ini kemungkinan disebabkan oleh senyawa tersebut masih belum murni, sehingga perlu dilakukan fraksinasi dan pemurnian dengan harapan agar didapat nilai $\mathrm{IC}_{50}$ dari senyawa spesifik yang memiliki aktivitas antioksidan yang lebih kuat. Adanya kandungan metabolit sekunder selain flavonoid kemungkin tidak memberikan respon sinergis sehingga aktivitas antioksidan yang dihasilkan lemah

\section{Pemisahan dan Pemurnian}

Pemisahan ekstrak kental etil asetat daun pranajiwa dilakukan dengan menggunakan kromatografi kolom dengan eluen $n$-heksana : kloroform : etanol (20:1:1) menghasilkan 100 fraksi yang selanjutnya diuji dengan kromatografi lapis tipis. Fraksi -fraksi yang menunjukkan noda dengan pola pemisahan yang sama digabungkan sehingga diperoleh 11 kelompok fraksi $\left(\mathrm{F}_{\mathrm{A}}, \mathrm{F}_{\mathrm{B}}, \mathrm{F}_{\mathrm{C}}, \mathrm{F}_{\mathrm{D}}, \mathrm{F}_{\mathrm{E}}, \mathrm{F}_{\mathrm{F}}, \mathrm{F}_{\mathrm{G}}\right.$, $\left.F_{H}, F_{I}, F_{J}, F_{K}\right)$. Berdasarkan uji fitokimia, fraksi $\mathrm{E}$ menunjukkan positif flavonoid. Fraksi E diuji kemurnian secara kromatografi lapis tipis dengan berbagai eluen menunjukkan noda tunggal sehingga fraksi $\mathrm{E}$ dapat dinyatakan murni secara KLT dan dilanjutkan pada identifikasi dengan spektrofotometri UV-Vis dan IR.

\section{Analisis Spektra Inframerah Isolat $F_{E}$}

Spektra yang dihasilkan oleh isolat $\mathrm{F}_{\mathrm{E}}$ menunjukkan adanya serapan-serapan yang khas untuk beberapa gugus fungsi, diantaranya adalah pada bilangan gelombang 3483,44-3221,12 $\mathrm{cm}^{-1}$ yang menunjukkan adanya serapan melebar 


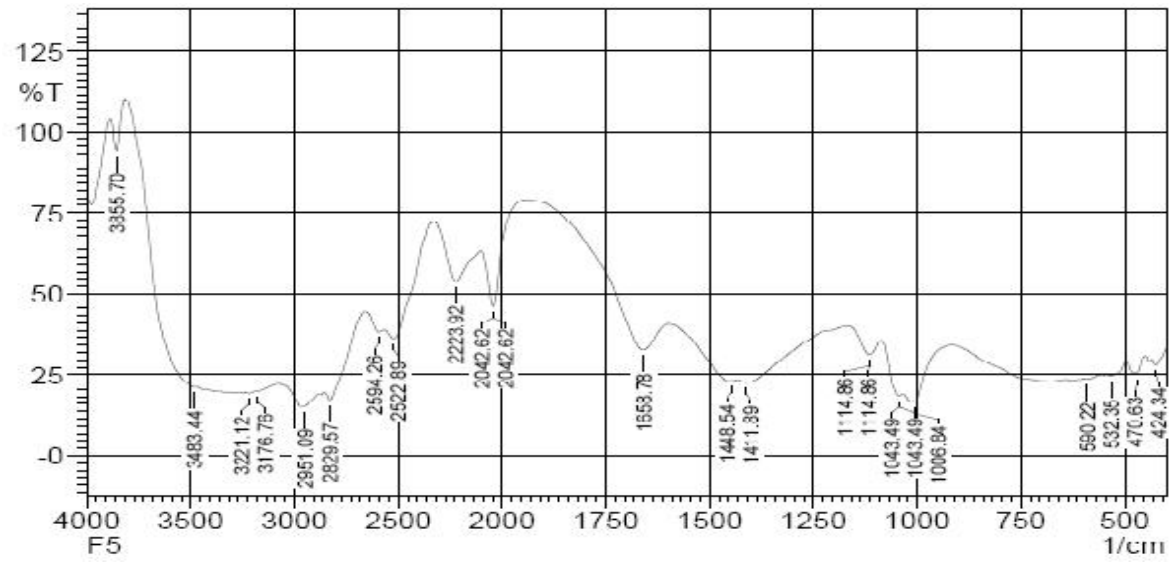

Gambar 3. Spektra FTIR isolat $F_{E}$

sebagai vibrasi ulur - $\mathrm{OH}$ yang mendukung adanya senyawa flavonoid yang memiliki gugus $\mathrm{OH}$ bebas dan diperkuat dengan vibrasi tekuk C-O alkohol pada daerah $1114,86-1006,84 \mathrm{~cm}^{-1}$. Vibrasi pada bilangan gelombang $3176,76 \mathrm{~cm}^{-1}$ menunjukkan adanya serapan ulur $\mathrm{C}-\mathrm{H}$ aromatik. Karakteristik lain yang mendukung adanya cincin aromatik ditunjukkan oleh serapan pada daerah bilangan gelombang $1658,78 \mathrm{~cm}^{-1}$ yang merupakan serapan dari regangan cincin $\mathrm{C}=\mathrm{C}$ aromatik sebagai gugus kromofor yang khas dari flavonoid dalam sistem ikatan terkonjugasi. Hal ini diperkuat dengan adanya vibrasi pada 590,22-424,34 $\mathrm{cm}^{-1}$ yang menunjukkan adanya gugus $\mathrm{C}=\mathrm{C}$ aromatik. Vibrasi pada 2951,09-2829,57 $\mathrm{cm}^{-1}$ menunjukkan adanya vibrasi $\mathrm{CH}$ alifatik stretching untuk gugus metil $\mathrm{CH}_{3}$ dan metilena $\mathrm{CH}_{2}$. Hal ini diperkuat dengan adanya vibrasi pada 1448,54-1411,89 $\mathrm{cm}^{-1}$ yang menunjukkan gugus $\mathrm{CH}$ alifatik. Pita serapan yang tajam pada daerah bilangan gelombang $1658,78 \mathrm{~cm}^{-1}$ dengan pita serapan yanga tajam juga menunjukkan adanya gugus $\mathrm{C}=\mathrm{O}$ [20]. Hal ini didukung dengan penelitian mengenai isolasi dan identifikasi senyawa kaempferol pada daun jangkang (Homalocladium platycladum (F. Muell) Bailey) pada spektra inframerah menunjukkan adanya pita $\mathrm{C}=\mathrm{C}$ dan $\mathrm{C}=\mathrm{O}$ terlihat tumpang tindih di sekitar 1600,0 $\mathrm{cm}-1$. Pita $\mathrm{C}=\mathrm{O}$ yang muncul pada bilangan gelombang yang rendah tersebut disebabkan karena resonansi pada struktur $\alpha, \beta-$ unsaturated carbonyl dan terbentuknya ikatan hidrogen intermolekuler [11].

Hasil uji konfirmasi dengan spektrofometer FTIR menunjukkan bahwa pada isolat $F_{E}$ terdapat vibrasi gugus $-\mathrm{OH}, \mathrm{C}-\mathrm{H}$ aromatik, $\mathrm{C}=\mathrm{C}$ aromatik, $\mathrm{C}=\mathrm{O}, \mathrm{C}-\mathrm{O}$, dan $\mathrm{C}-\mathrm{H}$ alifatik stretching. Hal tersebut memperkuat dugaan senyawa flavonoid golongan flavonol yaitu kaempferol atau kuersetin pada isolat $\mathrm{F}_{\mathrm{E}}$.

\section{Analisis Spektrum UV-Vis Isolat $\mathbf{F}_{\mathbf{E}}$ \\ Karakteristik isolat $\mathrm{F}_{\mathrm{E}}$ dengan} spektrofotometer UV-Vis dengan pelarut etanol memberikan serapan maksimum pada panjang gelombang $269 \mathrm{~nm}$ (pita II) dan $362 \mathrm{~nm}$ (pita I). Serapan maksimum yang terjadi pada panjang gelombang yang ditunjukkan oleh pita II disebabkan oleh adanya transisi elektronik dari $\mathrm{n}-\pi^{*}$ yang menunjukkan keberadaan gugus kromofor tunggal seperti ikatan $\mathrm{C}=\mathrm{O}$ [12]. Sedangkan serapan maksimum yang terjadi pada panjang gelombang yang ditunjukkan oleh pita I disebabkan oleh adanya eksitasi elektron dari $\pi-\pi^{*}$ yang menunjukkan keberadaan gugus kromofor $\mathrm{C}=\mathrm{C}$ terkonjugasi [13]. Berdasarkan studi literatur, senyawa yang memiliki spektrum UV-Vis pada pita II dengan rentang $\lambda_{\text {maks }} 250-280 \mathrm{~nm}$ dan pita I dengan $\lambda_{\text {maks }} 350-385 \mathrm{~nm}$ termasuk ke dalam golongan flavonol (3-OH bebas) [12]. Pola oksigenasi dari flavonoid dapat ditunjukkan dengan penambahan pereaksi geser pada isolat $\mathrm{F}_{\mathrm{E}}$. Hasil pengukuran spektrum UV-Vis dari 


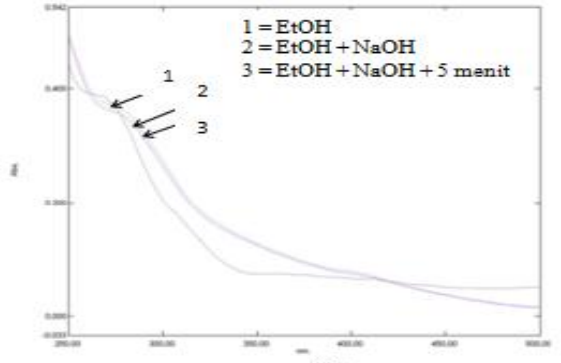

(a)

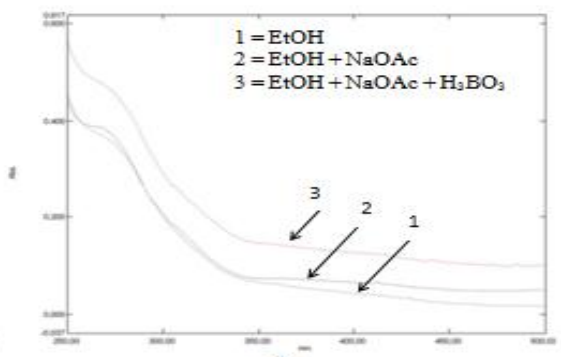

(b)

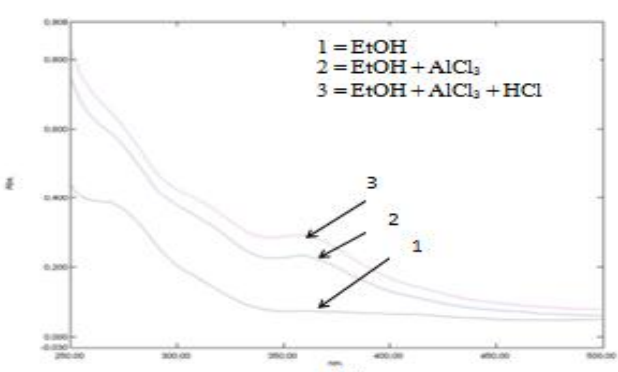

(c)

Gambar 2. Pergeseran spektrum UV-Vis pada isolat $\mathrm{F}_{\mathrm{E}}$ dengan penambahan pereaksi geser (a) $\mathrm{NaOH}$ dan $\mathrm{NaOH}+5$ menit, (b) $\mathrm{NaOAc}$ dan $\mathrm{NaOAc}+\mathrm{H}_{3} \mathrm{BO}_{3}$, dan (c) $\mathrm{AlCl}_{3}$ dan $\mathrm{AlCl}_{3}+\mathrm{HCl}$

isolat $\mathrm{F}_{\mathrm{E}}$ dengan penambahan pereaksi geser dapat dilihat pada Gambar 2.

Pereaksi geser natrium hidroksida $(\mathrm{NaOH})$ merupakan basa kuat yang dipergunakan untuk mendeteksi adanya gugus hidroksi. Hasil penambahan pereaksi geser $\mathrm{NaOH}$ pada isolat $\mathrm{F}_{\mathrm{E}}$ menghasilkan pergeseran batokromik yang jelas pada pita I sebesar $44,4 \mathrm{~nm}$, sedangkan pada pita II didapatkan pergeseran batokromik sebesar $7 \mathrm{~nm}$. Adanya pergeseran batokromik pada pita I mengindikasikan adanya gugus hidroksi pada posisi atom C nomor 4' pada cincin $\mathrm{B}$, sedangkan pita II mengindikasikan adanya gugus hidroksi pada cincin A yaitu pada atom $\mathrm{C}$ nomor 7 [12]. Pergeseran panjang gelombang spektra UV-Vis isolat $F_{\mathrm{E}}$ dapat dilihat pada Tabel 3.

Penambahan pereaksi NaOAc akan bereaksi dengan mengionisasi gugus hidroksil flavonoid yang paling tahan asam yaitu gugus 7-OH dan menyebabkan terjadinya pergeseran batokromik pada pita II, sedangkan penambahan $\mathrm{H}_{3} \mathrm{BO}_{3}$ (asam borat) akan menjembatani kedua gugus hidroksil pada gugus orto-dihidroksi sehingga terbentuk kompleks borat. Dari penambahan pereaksi $\mathrm{NaOAc}$ dan $\mathrm{NaOAc}$ $+\mathrm{H}_{3} \mathrm{BO}_{3}$ pada isolat $\mathrm{F}_{\mathrm{E}}$ menunjukkan adanya pergeseran batokromik pada pita I sebesar 29,6 nm dan pita II sebesar 7,8 nm yang mengindikasikan adanya gugus $7-\mathrm{OH}$ dan adanya gugus ortodihidroksi pada cincin B yaitu pada atom C-3' dan C-4' [12].

Penambahan pereaksi geser aluminium klorida $\left(\mathrm{AlCl}_{3}\right)$ akan membentuk kompleks dengan gugus ortodihidroksi maupun hidroksi keton. Sedangkan pada penambahan $\mathrm{HCl}$ akan mengakibatkan kompleks terurai kembali karena adanya $\mathrm{Al}$ tidak stabil yang terbentuk pada gugus orto-dihidroksi. Pada penambahan pereaksi aluminium klorida $\left(\mathrm{AlCl}_{3}\right)$ menghasilkan pergeseran batokromik sebesar $0,8 \mathrm{~nm}$ pada pita II, selanjutnya pada penambahan pereaksi geser asam klorida ( $\mathrm{HCl})$ menunjukkan pergeseran batokromik sebesar 1,4 nm. Adanya pergeseran batokromik pada pita II setelah penambahan pereaksi $\mathrm{AlCl}_{3}+\mathrm{HCl}$ sebesar 1,4 $\mathrm{nm}$ mengindikasikan adanya 
Tabel 3. Pergeseran Panjang Gelombang Spektra UV-Vis Isolat $F_{E}$

\begin{tabular}{|c|c|c|c|c|c|}
\hline \multirow[t]{2}{*}{ Pereaksi geser } & \multicolumn{2}{|c|}{$\begin{array}{c}\text { Panjang gelombang } \\
\lambda_{\text {maks }}(\mathrm{nm})\end{array}$} & \multicolumn{2}{|c|}{$\begin{array}{c}\text { Geseran panjang } \\
\text { gelombang } \lambda_{\text {maks }} \\
(\mathrm{nm})\end{array}$} & \multirow{2}{*}{ Petunjuk penafsiran* } \\
\hline & Pita I & Pita II & Pita I & Pita II & \\
\hline Etanol & 362,00 & 269,00 & - & - & $\begin{array}{c}\text { Flavonol } \\
\text { (3-OH bebas) }\end{array}$ \\
\hline $\mathrm{Etanol}+\mathrm{NaOH}$ & 406,40 & 276,00 & $+44,4$ & +7 & \multirow[t]{2}{*}{$4^{\prime}-\mathrm{OH}$} \\
\hline Etanol $+\mathrm{NaOH}+5$ menit & 406,40 & 276,00 & $+44,4$ & +7 & \\
\hline Etanol $+\mathrm{NaOAc}$ & 391,60 & 276,80 & $+29,6$ & $+7,8$ & $7-\mathrm{OH}$ \\
\hline $\mathrm{Etanol}+\mathrm{NaOAc}+\mathrm{H}_{3} \mathrm{BO}_{3}$ & 391,60 & 276,80 & $+29,6$ & $+7,8$ & o-diOH pada cincin B \\
\hline $\mathrm{Etanol}+\mathrm{AlCl}_{3}$ & $\begin{array}{l}358,40 \\
314,80\end{array}$ & 269,80 & $\begin{array}{c}-3,6 \\
-47,2\end{array}$ & $+0,8$ & \multirow[t]{2}{*}{$\begin{array}{c}\text { o-diOH pada cincin B } \\
\text { dan } 5-\mathrm{OH}\end{array}$} \\
\hline $\mathrm{Etanol}+\mathrm{AlCl}_{3}+\mathrm{HCl}$ & 355,60 & 270,40 & $-6,4$ & $+1,4$ & \\
\hline
\end{tabular}

gugus hidroksi pada cincin A yaitu pada C5. Sedangkan pada pita I menghasilkan pergeseran hipsokromik sebesar 3,6 nm dan pita Ia sebesar 47,2 $\mathrm{nm}$ setelah penambahan pereaksi geser $\mathrm{AlCl}_{3}$ dan $\mathrm{AlCl}_{3}+\mathrm{HCl}$. Hal ini menunjukkan adanya gugus ortodihidroksi pada cincin B [12, 14]. Berdasarkan hasil identifikasi isolat $F_{E}$ dengan spektrofotometer UV-Vis yang dikonfirmasi dengan hasil spektra FTIR serta penambahan pereaksi geser, dapat diduga kandungan senyawa flavonoid golongan flavonol. Isolat $\mathrm{F}_{\mathrm{E}}$ diduga mengandung senyawa flavonoid yaitu 3,5,7,3',4'-pentahidroksi flavonol.

\section{KESIMPULAN}

Berdasarkan hasil penelitian ini dapat disimpulkan bahwa ekstrak etil asetat daun pranajiwa mengandung senyawa antioksidan golongan flavonoid yang diduga merupakan senyawa $3,5,7,3^{\prime}, 4^{\prime}$ pentahidroksi flavonol.

\section{UCAPAN TERIMAKASIH}

Pada kesempatan ini penulis menyampaikan terimakasih kepada bapak Dr. I Wayan Gede Gunawan, S.Si., M.Si., ibu Dra. Ni Made Puspawati, M.Phil., Ph.D, bapak Prof. Dr. Drs. I Made Dira Swantara, M.Si., bapak Dr. Drs. I Made Oka Adi Parwata, M.Si., dan Dr. Dra. Wiwik Susanah Rita, M.Si dan yang lainnya yang telah memberikan dukungan dan masukan dalam penelitian dan penulisan jurnal ini.

\section{DAFTAR PUSTAKA}

[1] Heyne, K. 1987. Tumbuhan Berguna Indonesia III. (Tjetjep Badan Penelitian dan Pengembangan Kehutanan Pentj). Jakarta: Yayasan Sarana Wana Jaya.

[2] Ardaka, I.M., Tirta, I.G., Dan Darma, I.D.P. 2011. Pengaruh Jumlah Ruas Dan Zat Pengatur Tumbuh Terhadap Pertumbuhan Stek Pranajiwa (Euchresta horsfieldii (Lesch.) Benn). Jurnal Penelitian Hutan Tanaman. 8(2): 81-87. 
[3] Matsuura Nobuyasu, Iinuma Munekazu, Tanaka Toshiyuki. 1994. Phylogenetic Analysis in Genus Euchresta Based on Secondary Metabolites. Biochemical Systematic and Ecology. 22(6):621-629.

[4] Kandaswani, C. dan Middleton, E. 1997. Flavonoids as Antioxidant. In: Shahidi, F., editor. Natural Antioxidant Chemistry Health Effects and Applications. Champaign Illions: AOAC Press.

[5] Widayanti, N.P. 2015. "Identifikasi Fraksi Aktif Ekstrak N-Butanol Kulit Terong Belanda (Solanum betaceum Cav.) dan Uji Aktivitasnya Terhadap Superoksida Dismutase Pada Tikus Di Bawah Kondisi Stres" (tesis). Denpasar: Universitas Udayana.

[6] Sari, A. I., Gunawan, I W.G., dan Putra, K.G.D. 2015. Kapasitas Antioksidan Senyawa Golongan Triterpenoid Pada Daun Pranajiwa (Euchresta horsfieldii Lesch Benn). Jurnal Kimia 9 (1) : 61-66.

[7] Tirta, I.G., Ardaka, I.M., Dan Darma, I.D.P. 2010. Studi Fenologi Dan Senyawa Kimia Pronojiwo (Euchresta horsfieldii Lesch Benn). Bul. Littro. 21(1): 28 - 36.
[8] Chang, C., Yang, M. and Wen, H.C.J. 2002. Estimation of Total Flavonoid Content in Propolis by Two Complementary Colorinetric Methods. J.Food Drug Anal. 10: 178182.

[9] Almey, A., Khan A.J., Zahir S., Suleiman M., Aisyah, R.K. 2010. Total Phenolic Content and Primary Antioxidan Activity of Methanolic and Ethanolic Extract of Aromatic Plants' Leaves. International Food Research Journal. 17:1077-1084. [10] Molyneux, P. 2004.The use of the stable free radical diphenylpicrylhydrazyl (DPPH) for estimating antioxidant activity. J. Sci. Technol. Songklanakarin. 26(2): 211219.

[11] Cut Nuria, M., Wahyono, dan Susidarti, R.A. 2011. Isolasi dan Identifikasi Kaempferol dari Daun Jangkang (Homalocladium platycladum (F. Muell) Bailey) serta Aktivitas Antibakterinya. Farmasi Indonesia. UGM Yogyakarta, 22(1): $1-8$ 
Volume 5, Nomor 1, Juli 2017 